\title{
MULTIGERACIONALIDADE E O PROCESSO DE ENFRENTAMENTO DA VIOLÊNCIA CONTRA A MULHER: ESTUDOS DE CASO
} MULTIGENERATIONAL AND THE COPING PROCESS IN VIOLENCE AGAINST WOMEN: CASE STUDIES

\author{
LILA MARIA GADONI-COSTA \\ (UNIVERSIDADE FEDERAL DO RIO GRANDE DO SUL, Porto Alegre, RS - Brasil).
}

\begin{abstract}
RESUMEN
La violencia contra la mujer constituye un factor de estrés grave que afecta la salud mental de la víctima. En este estudio se investigó el proceso de afrontamiento así como el tema de la multigeneracionalidad, a partir de dos casos de mujeres víctimas de violencia doméstica. Los dos casos se configuran como de extrema violencia, tanto en las familias de origen cuanto en las familias actuales, caracterizando la multigeracionalidad. Para afrontar la situación de violencia, las entrevistadas utilizaron estrategias de afrontamiento focalizado tanto en el problema como en la emoción, y demostraron tener recursos personales, además de recursos socio-ecológicos, como la comisaría especializada y el apoyo de la red social en el rescate de la autoconfianza, lo que confirma la importancia de ese tipo de recursos en el afrontamiento de la violencia conyugal.
\end{abstract}

PALABRAS CLAVE: Violencia, mujer, multigeneracionalidad, afrontamiento.

\section{ABSTRACT}

Violence against women constitutes a severe stressor that affects the mental health of the victim. This study investigated the coping process and the multigenerational phenomenon from two cases of women victims of domestic violence. Both are configured as extreme violence, both in families of origin and current families, featuring a multigenerational. To deal with the violence, the women interviewed have undertaken coping strategies, problem-focused as much as emotion-focused, and relied on personal resources and socio-ecological, as women's police station and social support network in the rescue of confidence, confirming the importance of this strategies in fighting domestic violence.

KEY WORDS: Violence, women, multigenerational, coping. 
A violência contra a mulher é um fenômeno que perpassa todas as classes sociais e independe de idade ou escolaridade. Por tratar-se de uma questão multifacetada e de alta prevalência, pesquisadores de diversas áreas têm se ocupado dessa temática (Grossi \& Aguinsky, 2001). Entre as formas de violência sofridas pela mulher, destacase a violência que ocorre no âmbito privado e é perpetrada por parceiro íntimo, também denominada violência doméstica. Conforme Calvete, Corral e Estévez (2008), esta forma de violência constitui-se em um estressor severo, que afeta negativamente a saúde mental da vítima. No Brasil, existe uma lei contra a violência doméstica, conhecida como Lei Maria da Penha (Lei 11.340/2006, disponível

em

http://www.planalto.gov.br/ccivil_03/_Ato200 4-2006/2006/Lei/L11340.htm), que orienta as práticas de atendimento multidisciplinar, tanto nas delegacias especializadas como nos serviços de saúde.

$\mathrm{Na}$ violência conjugal, o agressor, que em geral é o homem, busca maneiras diversas para exercer o controle sobre sua parceira. Segundo a Organização Mundial da Saúde, uma em cada seis mulheres no mundo sofre violência doméstica, sendo que em $60 \%$ dos casos, a violência foi perpetrada por marido ou companheiro (OMS, 2005). No estudo de Blay (2003), sobre registros de homicídio de mulheres em delegacias de polícia de São Paulo, $90 \%$ dos autores eram homens. As agressões físicas severas, frequentes ou ocasionais, servem para incutir o medo e o terror sobre a vítima. A violência psicológica aparece em forma de controle coercitivo, a fim de manter a mulher isolada, economicamente dependente e emocionalmente abalada (Arriaga \& Capezza, 2005). Os agressores muitas vezes se tornam mais violentos ao longo do tempo e apresentam outros problemas de comportamento, tais como transtornos de personalidade ou abuso de drogas. Johnson e Ferraro (2000) denominam essa situação de "terrorismo íntimo". A causa provável é a necessidade de exercer poder sobre outra pessoa, estimulada por um forte senso de direitos patriarcais.

Fatores como cultura, gênero ou aspectos relacionais influenciam de forma direta a violência conjugal, em um processo dinâmico. Outros fatores são os mecanismos com os quais as mulheres podem contar de forma concreta, tais como: políticas públicas, atendimento especializado, rede de apoio social e independência financeira. Estudos destacam que, no Brasil, a criação das delegacias especializadas no atendimento à mulher, em 1985, e a promulgação da Lei Maria da Penha, em 2006, foram as principais contribuições nesse sentido (Debert \& Oliveira, 2007; Gadoni-Costa \& Dell'Aglio, 2009).

A violência provoca uma situação de intenso estresse na família, que comumente resulta em marcas físicas e psicológicas. Quando a violência ocorre entre o casal 0 assunto torna-se ainda mais complicado, devido aos efeitos que frequentemente se estendem em forma de multigeracionalidade (Takano, 2006). Na literatura especializada diferentes termos podem ser encontrados para descrever esse processo de transmissão dos legados familiares entre as gerações. Entre eles, destacam-se "transgeracionalidade","intergeracionalidade " e"multigeracionalidade" (Falcke \& Wagner, 2005). Na multigeracionalidade 0 adulto que vivenciou situação de violência familiar tende a reproduzi-la com seus próprios filhos, sendo que tais experiências podem incluir violência física, emocional, sexual e negligência. Neste artigo será utilizado o termo multigeracionalidade para descrever a transmissão do legado da violência doméstica de uma geração para outra.

Os crimes praticados em família não têm testemunhas e são encobertos pelo silêncio das próprias vítimas (Ribeiro, Ferriani \& Reis, 2004). Quando uma criança recebe punição física, passa a perceber a si mesma como merecedora desse castigo, 
acreditando que fez algo errado. Ao longo do tempo essa crença é internalizada e poderá se repetir na geração seguinte. A criança exposta à violência tenderá a ter problemas relacionados à agressão em suas relações futuras (Carrasco, 2003). 0 ciclo da violência, segundo Muskat (2002) começa quando as crianças sofrem negligência ou abuso em suas casas e quando aprendem a partir da relação agressiva dos pais, que é através da violência que se resolvem os conflitos. A exposição das crianças à violência intrafamiliar contribui para 0 estabelecimento do ciclo da violência intergeracional (Algeri \& Souza, 2006; Carrasco, 2003; Muskat, 2002).

\section{O processo de enfrentamento (coping)}

As mulheres que vivem em situação de violência conjugal podem utilizar diferentes estratégias para reduzir ou eliminar as ameaças à sua segurança física e seu bem-estar emocional. Estas estratégias de enfrentamento (coping) dependem de variáveis individuais e ambientais. Conforme Lazarus e Folkman (1984), o termo coping refere-se a um conjunto de esforços cognitivos e comportamentais utilizados para lidar com demandas específicas, avaliadas pelo sujeito como além de suas possibilidades. As estratégias utilizadas dependem de recursos materiais, crenças, habilidades e apoio social de cada indivíduo.

O modelo de coping de Lazarus e Folkman (1984) propõe quatro conceitos principais: 1) é um processo que se dá entre 0 indivíduo e 0 ambiente; 2) tem função de administrar a situação estressora, ao invés de controlá-la; 3) pressupõe a noção de avaliação de como o fenômeno é percebido, interpretado e cognitivamente representado pela pessoa; 4) constitui-se em uma mobilização de esforço, através da qual a pessoa irá empreender esforços cognitivos e comportamentais para administrar as demandas internas ou externas que surgem da sua interação com o ambiente.

$O$ enfrentamento pode ser centrado no problema ou na emoção e depende do repertório individual, bem como de experiências anteriores. 0 centrado no problema busca promover mudanças no ambiente e é mais utilizado quando essas mudanças são percebidas como possíveis. O centrado na emoção visa diminuir a sensação de desconforto emocional e é mais usado em situações percebidas como difíceis de mudar. Ambos ocorrem em situações estressantes e influenciamse mutuamente. Uma mesma pessoa pode utilizar tanto o enfrentamento focado no problema como na emoção e a eficácia de ambos pode variar, dependendo dos estressores envolvidos (Ravagnani, Domingos, \& Miyazaki, 2007).

Estudos recentes apontam que viver em situação de violência no âmbito doméstico pode se configurar como um importante estressor. Investigação realizada por Löbmann, Greve, Wetzels e Bosold (2003), sobre coping e violência contra a mulher, apontou que vários mecanismos são capazes de amenizar 0 impacto negativo dessa forma de vitimização, ou facilitar a superação dos efeitos posteriores. 0 processo de enfrentamento deve ser cuidadosamente avaliado no contexto em que se apresenta, pois este pode mediar e moderar as consequências da violência.

Boa parte da literatura sobre 0 enfrentamento da violência conjugal é focada em situações mais severas de violência, já citadas anteriormente como "terrorismo íntimo" (Johnson \& Ferraro, 2000). Com frequência são sugeridas intervenções, apoiadas na ideia de que a mulher vitimizada deve deixar 0 relacionamento violento. Porém, conforme salientam Arriaga e Capezza (2005), um olhar mais atento sobre a realidade mostra que nem todas as mulheres estão 
emocionalmente prontas para deixar seus companheiros agressores. Algumas das respostas apresentadas por essas mulheres incluem: crença de que são responsáveis por ajudar o parceiro ou de que a violência não vai se repetir; negação de que as atitudes do parceiro se caracterizem como violência ou minimização de sua intensidade; atribuição da violência a causas que estão além do controle do parceiro; e isolamento social cada vez maior a fim de evitar a vergonha por ser agredida.

O desafio, segundo Arriaga e Capezza (2005), é entender como as respostas que implicam em sofrimento psíquico, comprometimento emocional e dependência econômica, podem ser colocadas junto a um processo de enfrentamento mais global. Essas autoras questionam se é possivel identificar respostas que caracterizem 0 enfrentamento da violência conjugal, visto que diversos estudos sugerem um processo de enfrentamento mais generalizado. Esse processo é descrito da seguinte forma: inicialmente a mulher vivencia a sensação de deslealdade e traição acerca da violência inesperada. Depois tenta manter o parceiro feliz, a fim de evitar um rompante, e simultaneamente exibe uma ou mais das respostas citadas anteriormente. Em alguns casos, algum evento mais significativo desencadeia uma mudança na forma como a mulher percebe seu relacionamento. A partir daí, a noção da situação de violência passa a ter outra dimensão. A mulher pode tentar se separar mais de uma vez, tornando-se cada vez mais distanciada do parceiro, até que adquira recursos emocionais e financeiros para deixar definitivamente 0 relacionamento.

Estudos buscaram identificar estratégias de enfrentamento associadas às características positivas de vítimas que sobreviveram à violência (Parker \& Lee, 2007). Entre as estratégias utilizadas para enfrentar 0 fenômeno, principalmente quando sair do relacionamento abusivo não é uma opção viável, foram citadas ação direta, distração, reavaliação positiva sobre si mesma, definição de limites, planos de vida e busca por redes de apoio social, entre outras.

Tendo em vista a importância da compreensão do processo de enfrentamento e das estratégias empreendidas pelas mulheres em situação de violência doméstica, este estudo teve como objetivo investigar tais aspectos, bem como a presença da multigeracionalidade no fenômeno. Para tanto, foram realizados dois estudos de caso (Yin, 2005) envolvendo mulheres que buscaram atendimento psicológico em delegacia especializada.

\section{MÉTODO}

Foi realizado um estudo qualitativo, de cunho exploratório, a partir da metodologia de estudos de caso proposta por Yin (2005). Um estudo de caso é definido como uma investigação empírica que analisa um fenômeno contemporâneo dentro de seu contexto da vida real e permite que 0 fenômeno seja observado em profundidade, com variedade de detalhes e evidências, sendo que este tipo de delineamento preocupa-se com a compreensão do caso em si e não com a generalização para além dele (Yin, 2005). Foram estudados os casos de duas mulheres vítimas de violência conjugal que procuraram uma delegacia especializada para registro de ocorrência. Como critérios de inclusão foram considerados: 1) presença de histórico de violência perpetrada por parceiro, anterior ou atual, com convívio pelo período mínimo de um ano; e 2) estar em atendimento psicológico por pelo menos há dois meses com um estagiário ou profissional na delegacia onde os dados foram coletados.

A pesquisa foi aprovada pelo Comitê de Ética em Psicologia da UFRGS, sob 0 
protocolo $n^{0}$ 099/2008. Os dados foram coletados em um encontro com cada participante, através de entrevista semiestruturada individual, com duração de uma hora e meia, aproximadamente. As entrevistas foram realizadas na própria delegacia, após assinatura do Termo de Consentimento Livre e Esclarecido, e foram gravadas para posterior transcrição $\mathrm{e}$ análise de conteúdo. As entrevistas tinham por objetivo investigar a percepção das mulheres vítimas quanto à violência sofrida, as estratégias utilizadas para 0 enfrentamento do fenômeno, os sentimentos que emergiram no processo e os resultados obtidos através dessas estratégias.

As unidades de análise foram definidas a posteriori, a partir da análise qualitativa das respostas das participantes, efetuando-se recortes dos conteúdos das falas, tais como palavras, expressões ou frases que se referiam a temas específicos e que foram apreciados com o objetivo de esclarecer as semelhanças e as diferenças entre os casos (Laville \& Dionne, 1999; Yin, 2005). A partir disso, foram definidas duas unidades de análise para direcionar a discussão: multigeracionalidade e estratégias de enfrentamento. A compreensão dos resultados considerou como base teórica os estudos sobre processos de stress e coping, a partir do modelo de Lazarus e Folkman (1984), e pesquisas atuais que consideram 0 enfrentamento como um processo complexo e dinâmico.

\section{RESULTADOS}

Os casos são apresentados a partir da descrição geral e da história de cada uma das participantes, com nomes fictícios.

\section{Caso 1:}

Marlene tem 48 anos e foi casada com Rui por 24 anos, com quem tem um filho de 22 anos. 0 casal se separou há sete meses e ela foi morar com o filho. Marlene trabalha com vendas e tem renda suficiente para se manter sem ajuda do ex-marido.

O pai de Marlene era rígido, autoritário e bebia com frequência. A mãe sofreu violência física e psicológica ao longo dos anos, sem reagir, modelo reproduzido por Marlene em seu casamento. Aos vinte anos, Marlene perdeu uma amiga e entrou em depressão. Viajou por recomendação médica e, nessa viagem, conheceu Rui, com quem casou pouco tempo depois. A mãe dele era controladora e se intrometia no relacionamento do filho, que era extremante ciumento.

Após um ano e meio de casada Marlene engravidou sem querer. Depois do parto teve depressão puerperal. Sentiase sobrecarregada e preocupava-se em manter a casa impecável para quando 0 marido chegasse do trabalho. Passado algum tempo, Marlene decidiu trabalhar com vendas. A situação financeira melhorou e o relacionamento entrou em crise. A primeira agressão física foi por ciúmes e passaram a ficar mais intensas por volta do nono ano de casamento, a partir da primeira reação de Marlene depois de uma briga. Rui saiu de casa e Marlene entrou novamente em depressão. Apesar da separação eles continuaram a trabalhar juntos com as vendas. Marlene resolveu perdoar e durante um mês viveram em "lua-de-mel", mas logo depois as agressões físicas recomeçaram.

Há alguns anos atrás, Marlene decidiu denunciar Rui pelas agressões. Quando voltou para casa, comunicou sua decisão, ao que Rui respondeu com ameaças de morte. Marlene não registrou outras ocorrências depois disso, por medo de que ele pudesse ter uma reação extremada contra ela.

Marlene não compartilhava com ninguém a situação de violência, pois se sentia envergonhada. Passava períodos sem falar nada que pudesse contrariar 0 
marido a fim de evitar as agressões. Submeteu-se a muitos sacrifícios e assumiu afazeres que iam além de suas possibilidades físicas. Apesar da situação, Marlene e Rui não falavam em separação. Ele passou a se relacionar com outra mulher e um dia, após uma briga com muitas agressões físicas, Marlene decidiu procurar a delegacia da mulher.

Ao avaliar seu relacionamento, Marlene percebe que se anulou em nome da manutenção do casamento. Consideravase "uma máquina de trabalhar" e reconhece que trabalhava tanto para ser valorizada. Apesar disso, ainda sente-se culpada por tudo. Para ela, contar com a delegacia da mulher, a Lei Maria da Penha e 0 atendimento psicológico foi importante no momento de separação.

Caso 2:

Maria, 45 anos, é a sexta filha de uma família de quinze irmãos. Vive há 23 anos com José, com quem teve três filhos. Ele é usuário de álcool e cocaína. Além dos filhos que teve com José, Maria teve antes uma filha com outro homem. A menina foi levada pelo pai biológico e ela nunca mais teve notícias. Maria cursou até a quinta série do ensino fundamental e não trabalha atualmente. Parou de trabalhar porque o companheiro tinha muito ciúme. Procurou a delegacia para a mulher por não suportar mais sofrer violência física e psicológica.

Maria e seu pai não tinham um bom relacionamento. Ele era alcoólatra e agredia os filhos e a mulher, que não reagia diante da situação de violência. Maria engravidou aos dezesseis anos. A família não aceitou e a mandou embora de casa. Ela não tinha para onde ir e passou por situações extremas até conseguir um emprego em uma casa de família, onde ficou até a filha nascer. Depois de algum tempo voltou para sua cidade de origem. $\mathrm{Na}$ volta, o pai de sua filha reivindicou a guarda da menina. Maria nunca mais viu a filha. Desiludida, foi embora novamente e conheceu seu atual companheiro, José, com quem foi viver cinco meses depois.

0 início do relacionamento foi bom, embora ele fizesse uso de álcool, maconha e cocaína. Passou a agredir Maria, que inicialmente não reagia. Com 0 tempo, a situação de violência se intensificou e ela passou a reagir. A primeira agressão física foi tão intensa que Maria foi parar em um hospital. Sentiu muita raiva de José, que pediu desculpas e prometeu que aquilo não se repetiria.

As brigas aconteciam por qualquer motivo, o que levava Maria a procurar maneiras diferentes de enfrentar a situação, inclusive não reagindo. $O$ fato dela não reagir diante das agressões não diminuiu a frequência nem a intensidade das mesmas. Ao longo do relacionamento, ela passou a ter problemas de saúde. Para lidar com a raiva, além de chorar, contava com 0 apoio das irmãs. Ela também buscou a igreja e a fé como formas de apoio.

Maria atribuiu as atitudes de José, além do uso de drogas, ao ciúme. Ela não podia demonstrar interesse em nada, pois ele sentia ciúme. Maria procurava buscar novas formas de enfrentamento para suportar o controle de José, como conversar com as vizinhas e não se preocupar em dar satisfações ao companheiro. Outra forma encontrada por ela para lidar com o estresse foi 0 cigarro. Em outras ocasiões tentava o diálogo ou se submetia ao sexo, mesmo sem querer, a fim de evitar novas agressões. Ela passou a sentir tanta raiva que chegou a pensar em matar José envenenado. A decisão de chamar a polícia veio depois de algum tempo, porém, sem resultados. Depois de cinco registros de ocorrência contra José, Maria decidiu pedir medidas protetivas devido à intensidade das agressões. 
Com o apoio de familiares, Maria se sentiu fortalecida para tomar decisões efetivas. Ela aguarda que José seja novamente retirado de casa para recomeçar a vida ao lado dos filhos.

\section{DISCUSSÃO}

A discussão será apresentada a partir das duas unidades de análise definidas: multigeracionalidade e estratégias de enfrentamento. Serão apresentados os aspectos particulares de cada caso, conforme as unidades de análise, sendo que as características comuns entre eles serão apresentadas na discussão integrada.

\section{Caso 1 - Multigeracionalidade}

Foi possível observar diversos aspectos relacionados ao fenômeno da multigeracionalidade no caso de Marlene, que vem de uma família em que a violência do pai contra a mãe era explícita. Sua mãe sofreu violência física e psicológica ao longo dos anos, sem reagir. Assim como a mãe, que ficava passiva diante das agressões, Marlene também não reagia. A ideia de que "no outro dia, tudo passa" levou Marlene a conviver com essa situação como algo natural, o que, segundo Carrasco (2003), pode levar a internalização de um padrão de funcionamento permeado por agressões no ambiente familiar. Durante o casamento com Rui, Marlene sofreu o mesmo tipo de violência a que sua mãe foi submetida e, como ela, suportou por muitos anos sem reagir. Testemunhar situações de violência entre os pais durante a infância continua sendo foco de estudos recentes, baseados em uma perspectiva de aprendizado que pressupõe que os indivíduos modelam seus próprios comportamentos a partir dos observados em suas famílias de origem (Siegel \& Williams, 2001).

Marlene deparou-se novamente com 0 modelo autoritário do pai, no convívio com o marido e a sogra. Nessas relações ela se colocou mais uma vez no papel de submissão, aceitando e atendendo as imposições e exigências. De acordo com Beeman (2001), fatores familiares, como estrutura instável e autoritarismo, podem prejudicar um ambiente acolhedor e adequado que minimizaria o impacto de experiências de violência durante a infância e adolescência. A probabilidade de vivenciar violência e situações abusivas na idade adulta é maior quando as próprias mães foram vitimizadas.

\section{Estratégias de enfrentamento}

Para fazer frente à situação de violência no casamento, Marlene fez uso de diferentes estratégias de enfrentamento, combinando estratégias focadas na emoção e no problema. O relacionamento entrou em crise quando Marlene começou a ganhar dinheiro com seu trabalho. As estratégias empreendidas por ela foram inicialmente focadas na emoção, a fim de diminuir a sensação de desconforto emocional e pelo fato de perceber a situação como difícil de mudar. Estratégias de inação apareceram nos relatos sobre os primeiros anos em que sofreu violência por parte do companheiro. Segundo Sabina e Tindale (2008), eventos percebidos como inevitáveis podem levar a utilização de estratégias de enfrentamento que consistem em aceitação e adaptação ao evento estressor.

Também foi utilizada a estratégia de agressão e de confronto direto quando Marlene reagiu com fúria contra o marido após uma briga. Segundo Goodman et al. (2005), o confronto direto como forma da mulher combater a violência não costuma ser bem sucedido. Quando a mulher utiliza essa forma de enfrentamento, é mais provável que as agressões continuem nessa linha de confronto. É comum que muitos homens agressores façam uso da violência como uma forma de manter 0 controle sobre a parceira. Se a mulher 
tentar subverter o controle de forma direta, o agressor pode redobrar seus esforços para manter o controle, através do uso da violencia.

A briga terminou com a saída de Rui de casa. Logo depois Marlene entrou em depressão. As estratégias de enfrentamento sem eficácia são consideradas como um fator de risco para depressão, pois tendem a reforçar 0 sentimento de incapacidade e menosvalia (Sabina \& Tindale, 2008). Características depressivas, tais como tristeza e autoimagem negativa, relatadas por Marlene, podem afetar a escolha das estratégias de enfrentamento, bem como a capacidade de avaliar sua eficácia, pois se constituem em características pessoais que podem atuar como mediadoras no processo.

Depois da separação, Marlene perdoou e voltou a viver com o marido. De acordo com Löbmann et al. (2003), em situação de violência doméstica, muitas vezes a mulher reprime a memória e se recusa a refletir sobre a situação de violência, como uma forma de enfrentamento focado na emoção. Após uma fase sem brigas, as agressões recomeçaram. Para lidar com a situação, Marlene empreendeu estratégias de evitação e afastamento, que podem ser consideradas como adaptativas quando evitam que as situações de estresse e conflito se agravem (Waldrop \& Resick, 2004).

Marlene atribuía sua tolerância e permanência na relação ao medo de ficar sozinha e ao filho. Segundo a literatura (Arriaga \& Capezza, 2005; Löbman et al., 2003; Sabina \& Tindale, 2008), a manutenção do relacionamento violento depende de um conjunto de variáveis, sendo que uma delas é a presença dos filhos. As vítimas, cujos filhos têm conhecimento da situação de violência, têm maior probabilidade de falar sobre a situação para alguém de fora. Por outro lado, a presença de filhos somada à dependência financeira podem ser fatores que contribuem para a permanência no relacionamento.

Marlene não compartilhava com ninguém a situação de violência. Passava períodos sem falar nada que pudesse contrariar o marido a fim de evitar as agressões. De acordo com Löbman et al. (2003), é comum que a mulher vítima de violência demonstre uma sequência particular de comportamento que tem por fim evitar uma nova explosão do cônjuge. Conforme esses autores, tal atitude permite que a mulher tenha a ideia de controle, o que, ao longo do tempo a leva a uma adaptação frente à situação de violência.

Depois de muitos anos sofrendo violência, Marlene empreendeu estratégias de enfrentamento mais focado no problema, buscando modificar o estressor, ao decidir denunciar Rui pelas agressões. Ao sofrer novas ameaças, desistiu por medo. Esses achados estão em consonância com a literatura, que aponta que as mulheres em situação de violência temem retaliações por parte dos agressores após buscar intervenções judiciais (Hart, 1993; Sabina \& Tindale, 2008). A decisão final de procurar a delegacia da mulher só se deu após uma briga onde as agressões foram intensas $e$ após Marlene constatar que Rui estava vivendo uma relação extraconjugal. Conforme Arriaga e Capezza (2005), eventos significativos podem desencadear mudanças na forma como 0 relacionamento é visto pela mulher. Esse novo olhar contribui para que ela adquira os recursos necessários para sair do relacionamento. Também foram observados diferentes sentimentos que emergiram ao longo desse processo. Inicialmente a surpresa pelas traições e agressões, sucedida pela reação agressiva e sentimento de raiva, além do ciúme e do medo decorrentes da 
autoestima abalada. Os sentimentos de incapacidade e inferioridade prevaleceram durante muito tempo. De acordo com Matud (2004), a autoestima tem um papel importante no enfrentamento das situações de estresse e seus efeitos negativos sobre a saúde, além de influenciar o bem-estar de forma direta ou indireta, através das estratégias de controle emocional. Com o tempo, Marlene resgatou a autoestima e reconstruiu a autoimagem, apoiada no sucesso profissional, na busca de autonomia e no apoio psicológico.

Marlene contou com recursos pessoais ao resgatar a autoestima e a crença de autoeficácia, além dos recursos socioecológicos, como a delegacia para a mulher, 0 atendimento psicológico e a retomada das relações sociais e de amizade. Apesar de buscar esses recursos, ao longo do relacionamento violento, Marlene se deu conta que fez pouca utilização da estratégia de apoio social, ao afirmar que se afastou dos amigos porque Rui não gostava deles. Viver em situação de violência por longos períodos pode contribuir para a utilização de estratégias negativas, que conduzem a sintomas e sofrimento psíquico. Além disso, o convívio em ambientes violentos leva ao aprendizado de que as estratégias negativas são aceitáveis e adaptativas dentro deste contexto (Dell'Aglio \& Deretti, 2005).

0 acompanhamento psicológico foi percebido por ela como suporte para 0 resgate de suas potencialidades $e$ fortalecimento pessoal, além de funcionar como apoio para enfrentar o medo que ela ainda sente de Rui. Assim, pode-se observar no caso de Marlene uma evolução no processo de enfrentamento à violência ao longo dos anos. Inicialmente usava estratégias mais passivas e focadas na emoção e passou a utilizar estratégias mais ativas e focadas no problema. Para essa mudança foi muito importante 0 resgate da autoestima, que se deu principalmente através do trabalho. Esses achados estão em consonância com a literatura, que aponta que mulheres que desenvolvem atividade profissional remunerada tendem a buscar estratégias mais eficazes para lidar com a violência (Debert \& Oliveira, 2007; Rabello \& Caldas Junior, 2007).

\section{Caso 2 - Multigeracionalidade}

Maria veio de uma família disfuncional, em que as relações eram baseadas em regras rígidas e permeadas por agressões e maus tratos. Ela tinha um relacionamento pouco afetivo com 0 pai, que era extremamente agressivo e exigente com os filhos. De acordo com Algeri e Souza (2006), o ciclo da violência contra crianças e adolescentes está vinculado ao relacionamento afetivo entre pais e filhos. Quando 0 afeto não está presente de forma clara, os filhos podem sentir-se ameaçados e sem valor. Crianças e adolescentes submetidos à violência de forma reiterada, como aconteceu com Maria, aprendem que os conflitos só podem ser resolvidos dessa maneira.

A mãe de Maria também era agredida pelo pai, que além de violento era alcoólatra. Maria sofria pela situação da mãe, com quem tinha um bom relacionamento. A identificação aparece de forma clara no relato de Maria, em que ela se vê igual à mãe, ao suportar a situação de violência sem reagir. Conforme Algeri e Souza (2006), a família que propicia a vivência de situações de violência aos filhos, no âmbito doméstico, determina que eles vivenciem também uma situação de extrema vulnerabilidade, com possibilidade de repetição desses padrões. Maria, assim como a mãe, buscou um parceiro agressor, dependente químico e pouco afetivo com os filhos, recomeçando assim um novo ciclo que leva à multigeracionalidade da violência. Estratégias de enfrentamento 
Diversas estratégias de enfrentamento foram utilizadas por Maria ao longo de seu relacionamento com José. Assim como no caso anterior, foram empreendidas estratégias focadas na emoção e no problema. Durante muito tempo a estratégia de ação agressiva, utilizada também como estratégia de sobrevivência, foi a mais empreendida por ela, ao revidar as agressões do companheiro. Segundo alguns autores, essa forma de enfrentamento pode ser vista como desadaptativa, visto que sua utilização traz resoluções somente em curto prazo (Dell'Aglio, 2000; Waldrop \& Resick, 2004).

Apesar da raiva, Maria ainda procurava encontrar respostas para as atitudes de José, atribuindo os fatos ao uso da cocaína. Depois das brigas, tentava conversar e pensar em alternativas, como a possibilidade de internação para tratar a dependência química do companheiro. Essa forma de enfrentamento pode ser vista como reavaliação positiva da situação, onde há a tentativa de reestruturação do problema, a fim de encontrar aspectos mais favoráveis, além da intenção de amenizar a gravidade da mesma (Rodrigues \& Chaves, 2008). Segundo alguns autores, reavaliar a situação de forma positiva pode encorajar a utilização de estratégias focadas no problema, e dessa forma, reavaliar a competência individual também de forma positiva (Seidl, Tróccoli, \& Zannon, 2001).

Estratégias de distração foram utilizadas por ela em diversos momentos. Depois das agressões, como forma de alívio da tensão, Maria relatou que fumava ainda mais. Esse tipo de estratégia centrada na emoção é dirigido a um nível somático de tensão emocional e tem a função de reduzir a sensação física desagradável do estado de estresse (Lazarus \& Folkman, 1984).

Maria se submetia ao sexo, mesmo contra sua vontade, como estratégia para evitar novas agressões motivadas pelo ciúme excessivo do companheiro. Ellsberg et al. (2001) salientam que o abuso físico muitas vezes é acompanhado por coerção sexual e quase sempre ocorre em um contexto de ciúme extremo e controle marital. Ela passou a ter problemas para dormir e dificuldades com a alimentação. Autores apontam que sintomas relacionados a perturbações do sono e transtornos alimentares são comuns em mulheres que vivem em situação de violência. Também são comuns fobias, sintomas depressivos, disfunção sexual, manifestações psicossomáticas e abuso de calmantes (Alves \& Coura-Filho, 2001).

As vivências relatadas por Maria referem-se a agressões extremas, marcadas por humilhações e desrespeito. Ela sentia tanta raiva que chegou a pensar em matar José envenenado ou se matar. Para Cunha (2008), a violência intensa pode levar a mulher a um ponto tal de desespero, que culmine em atos extremados como 0 homicídio ou 0 suicídio.

A decisão de chamar a polícia veio depois de algum tempo, porém, sem resultados. Depois de cinco tentativas e registros de ocorrência contra José, Maria decidiu pedir medidas protetivas, em consequência da intensidade das agressões e do apoio recebido da família. A estratégia de busca por apoio, segundo Danuluk e Tench (2007), é geralmente relacionada a resultados positivos. Swan e Sullivan (2009) salientam que um bom suporte social pode encorajar a mulher em situação de violência a empreender estratégias de enfrentamento focadas no problema.

Ao longo do processo de enfrentamento da situação de violência, Maria foi tomada por sentimentos intensos e recorrentes, tendo prevalecido a raiva pela impotência diante dos fatos, pela submissão e por não ter forças para mudar 
o rumo da situação. Maria sentiu raiva do pai e, ao sentir-se identificada com a mãe, reproduziu em seu próprio relacionamento o papel de mulher submissa e vitimizada. Segundo Gomes e Diniz (2008), a aceitação por parte da mulher, de um papel de submissão é fator determinante para que ela não perceba a situação de violência em que se encontra, contribuindo assim para manutenção do fenômeno.

Maria aceitou as imposições de José e abriu mão do trabalho e dos amigos. A dependência financeira e o trabalho são considerados como dois importantes fatores na permanência da mulher no relacionamento abusivo (Waldrop \& Resick, 2004). Sua vida ficou esvaziada de prazer, com muitos sentimentos negativos. Autores apontam que mulheres que vivenciam violência doméstica extrema experimentam, com maior frequência, ausência de bem-estar psíquico e adotam comportamentos de risco como tabagismo, entre outros, com maiores riscos de depressão, problemas de autoestima, ideação suicida e sentimentos de desesperança (Matud, 2004).

Maria vivenciou situações com privações de toda ordem desde muito cedo. Foi vítima e testemunha de violência doméstica na infância e na vida adulta, teve sua filha mais velha levada para longe sem nunca mais tê-la visto, sofreu privações materiais e afetivas, isolou-se dos amigos, deixou de trabalhar e tornouse totalmente dependente do parceiro agressor. Conforme apontam Waldrop e Resick (2004), um dos resultados cruciais de muitos relacionamentos violentos é a diminuição do contato da mulher vitimizada com os recursos que poderiam ajudá-la a enfrentar a violência, como ocorreu com Maria. Apesar de todo 0 sofrimento, Maria lutou para mudar de vida e resgatar a autonomia, o que elevou sua autoestima. Os planos de vida, a determinação de Maria em voltar a trabalhar e o desejo de resgatar o prazer nas atividades cotidianas, indicam que 0 processo de enfrentamento tem se mostrado positivo e refletem otimismo e esperança em uma vida com mais sentido e dignidade.

\section{DISCUSSÃO INTEGRADA DOS CASOS}

Os dois casos investigados se configuram como de extrema violência conjugal no âmbito doméstico, em que tanto a violência física como a psicológica se fez presente nas famílias de origem e nas famílias atuais, caracterizando a multigeracionalidade. Marlene e Maria tiveram um relacionamento difícil com a figura paterna, descrita como pouco afetiva, rígida, agressiva e autoritária. Os pais de ambas eram alcoólatras e a situação financeira era precária. Apesar do uso de álcool não ser um fator causal da violência doméstica, pode ser relacionado de forma significativa ao fenômeno. Sharps et al. (2003) sugerem que 0 alcoolismo severo aumenta o risco de vitimização de mulheres e seus filhos nos relacionamentos com parceiros íntimos.

Marlene e Maria presenciavam agressões por parte dos pais, contra suas mães, que suportavam caladas, como se 0 comportamento dos homens fosse algo "natural". De acordo com Carrasco (2003), a partir do momento em que se estabelece a crença, entre mães e filhas, de que 0 homem pode agredir, instala-se a hierarquia. 0 homem fica com o papel de dominador e a mulher com o papel de submissa, proporcionando a partir daí, um total desequilíbrio nas relações.

Estas mulheres suportaram as agressões durante muito tempo sem partilhar com outras pessoas. Waldrop e Resick (2004) sugerem que a duração do relacionamento abusivo é um importante fator, apesar de ser considerado com menos frequência que a intensidade, nos estudos sobre esforços de enfrentamento das mulheres. A duração da relação pode 
mudar as respostas de enfrentamento ao longo do tempo, visto que quanto mais tempo a mulher permanece nesse tipo de relacionamento, mais ela se sente compelida a fazer com que dê certo.

As consequências da violência apareceram na forma de sentimentos como culpa, medo, raiva, tristeza e perplexidade diante de suas próprias histórias. Os aspectos emocionais comuns às duas mulheres poderiam ser delineados a partir de algumas características: imaturidade emocional, dependência em relação aos companheiros agressores, insegurança, baixa autoestima, experiências de instabilidade vividas na infância, comportamento impulsivo, presença de multigeracionalidade, além de utilização de diferentes estratégias de enfrentamento para obter controle sobre 0 agressor e sobre a situação (Alves \& Coura-Filho, 2001; Schraiber et al., 2007).

Segundo Goodman e colaboradores (2005), estudos focados especificamente em estratégias utilizadas por mulheres para controlar a violência, demonstram que a quantidade e diversidade das estratégias empreendidas aumentam conforme a severidade da violência. PaisRibeiro e Santos (2001) concordam com essas colocações, ao apontar que as pessoas recorrem a estratégias diferentes, conforme a situação. Algumas utilizam simultaneamente várias estratégias em quase todas as situações estressantes, tanto focadas no problema como na emoção. Para esses autores, algumas estratégias mostram-se mais eficazes em situações de violência, tais como reavaliação positiva, ação agressiva, distanciamento e fuga/evitação. Estas estratégias pertencem ao grupo de estratégias focadas na emoção. Entre as estratégias focadas no problema os autores destacam: confronto, busca por suporte social, assumir responsabilidade e resolução do problema. Marlene empreendeu mais claramente estratégias de distanciamento, evitação, confronto, autocontrole e assumir a responsabilidade. Já Maria utilizou mais estratégias de ação agressiva, reavaliação positiva, distanciamento, evitação e busca por suporte social. O uso de determinadas estratégias de enfrentamento reflete os fatores pessoais e o contexto, assim como os resultados esperados por sua utilização (Goodman et al., 2005). Quando as estratégias empreendidas não levam ao fim da situação de violência, as mulheres podem desenvolver sentimentos de desamparo aprendido e interromper suas tentativas de utilizar as mesmas estratégias que já foram utilizadas sem sucesso (Waldrop \& Resick, 2004).

Durante o processo de enfrentamento empreendido por Marlene e Maria, foram tomadas decisões ativas e conscientes baseadas em circunstâncias diversas. Em consonância com estratégias apontadas por Lerner e Kennedy (2000), ambas deixaram os relacionamentos por períodos curtos a fim de sair da violência e demonstrar o descontentamento com a situação, e também para mostrar a falta de esperança quanto ao fim da violência. Essas idas e vindas não acontecem com a intenção de terminar o relacionamento, e sim de negociar o restabelecimento da relação em uma base de não violência (Lerner \& Kennedy, 2000).

Ao utilizar estratégias de enfrentamento adequadas ao momento de estresse, mesmo nas condições adversas a que foram submetidas, Marlene e Maria foram capazes de empreender mudanças, o que também foi resultado do resgate da autoestima. Dessa forma, observou-se, através dos casos estudados, que 0 enfrentamento avaliado como um processo é dinâmico e modifica-se de acordo com as avaliações e reavaliações feitas continuamente sobre 0 evento estressor (Lazarus \& Folkman, 1984). Sendo assim, os mecanismos de enfrentamento devem ser compreendidos 
dentro de um contexto específico, nesse caso, a violência doméstica.

\section{CONCLUSÕES}

As estratégias utilizadas pelas mulheres para interromper, prevenir ou impedir situações de violência presentes em suas vidas, podem também ser entendidas como recursos, visto que são opções que as mulheres têm à disposição, para fazer frente à violência (Goodman et al., 2005). Como observado nos casos de Marlene e Maria, as estratégias podem ter o objetivo de aplacar a violência e mudar a situação sem que o agressor perca seu senso de controle ou podem ser estratégias que buscam a resistência, com o objetivo de modificar o comportamento agressivo e, se possivel, equilibrar 0 poder no relacionamento, desafiando o senso de controle do agressor. Folkman e Moskowitz (2004) destacam que 0 enfrentamento é um processo complexo e dinâmico e, para uma compreensão mais apurada, é necessário 0 estudo de variáveis que dizem respeito à pessoa envolvida, ao meio em que ela se desenvolve e à relação com esse meio.

Para a maioria das mulheres em situação de violência, a decisão de sair do relacionamento não é tomada de forma repentina e decisiva. Pode se estender no tempo e representa uma decisão difícil (Lerner \& Kennedy, 2000). Nem todas as mulheres desejam romper 0 relacionamento com o parceiro agressor e, quando o fazem, muitas vezes retornam para ele, como aconteceu com Marlene e Maria.

A identificação e o fortalecimento de fatores protetivos, no processo de enfrentamento da violência conjugal, são importantes para a prevenção e intervenção nestes casos. Através da estimulação e do treinamento de recursos de enfrentamento, crenças distorcidas poderão ser alteradas e 0 desenvolvimento de um novo repertório de enfrentamento poderá auxiliar e promover melhores resultados. Dessa forma, é importante que 0 processo de enfrentamento seja considerado no campo das pesquisas sobre violência contra a mulher. Outra questão relevante a ser considerada é a multigeracionalidade da violência doméstica. A identificação do ciclo que se estabelece nas famílias que vivem em situação de violência é determinante para que essa experiência não se repita geração após geração. São necessários esforços nos diferentes âmbitos da sociedade no sentido de romper este ciclo, bem como para auxiliar as mulheres a compreender a dimensão do mesmo.

Considerando as limitações deste estudo, destaca-se a importância de investigações com amostras maiores e novos delineamentos, a fim de que os resultados possam ser generalizados e 0 processo em questão possa ser mais bem compreendido. Os estudos empíricos sobre 0 processo de enfrentamento (coping) e as estratégias empreendidas por mulheres em situação de violência doméstica ainda são escassos no Brasil. Dessa forma, considera-se que esse seja o principal aspecto e contribuição deste estudo. Ampliar o entendimento sobre os processos de vitimização e enfrentamento de mulheres frente à violência doméstica pode trazer subsídios para programas de capacitação de profissionais que lidam com esta população, assim como para a proposição de projetos de intervenção e promoção de saúde junto a essas mulheres. 


\section{REFERENCIAS}

Algeri, S., \& Souza, L. (2006). Violência contra crianças e adolescentes: um desafio no cotidiano da equipe de enfermagem. Revista LatinoAmericana de Enfermagem, 14(4), 625-631.

Alves, A. M., \& Coura-Filho, P. (2001). Avaliação das ações de atenção às mulheres sob violência no espaço familiar, atendidas no Centro de Apoio à Mulher (Belo Horizonte), entre 1996 e 1998. Ciência e Saúde Coletiva, 6(1), 243-257.

Arriaga, X. \& Capezza, N. (2005). Targets of partner violence: The importance of understanding coping trajectories. Journal of Interpersonal Violence, 20(1), 89-99.

Beeman, S. K. (2001). Critical issues in research on social networks and social supports of children exposed to domestic violence. Em J. L. Edleson \& S. A. Graham-Berman (Orgs.), Domestic violence in the lives of children (pp. 219-234).Washington, DC: American Psychological Association.

Blay, E. A. (2003). Violência contra a mulher e políticas públicas. Estudos Avançados, 17(49), 87-98.

Calvete, E., Corral, S., \& Estévez, A. (2008). Coping as a mediator and moderator between intimate partner violence and symptons of anxiety and depression. Violence Against Women, 14(8), 886-904.

Carrasco, L. (2003). A mulher vítima de violência conjugal: Uma perspectiva transgeracional. Tese de Doutorado, Programa de Pós-Graduação em Psicologia, Pontifícia Universidade Católica de Porto Alegre (PUCRS), Porto Alegre, RS.

Cunha, T. (2008). Violência conjugal: Os ricos também batem. UEPG Ciências Humanas, Ciências Sociais Aplicadas, Linguística, Letras e Artes, 16(1), 167-176.
Danuluk, J. \& Tench, E. (2007). Long-term adjustment of infertile couples following unsuccessful medical intervention. Journal of Counseling and Development, 85, 89-100.

Debert, G. \& Oliveira, M. (2007). Os modelos conciliatórios de solução de conflitos e a "violência doméstica". Cadernos Pagu, 29, 305-337.

Dell'Aglio, D. D. \& Deretti, L. (2005). Estratégias de coping em situações de violência no desenvolvimento de crianças e adolescentes. Em C. S. Hutz (Org.), Violência e Risco na Infância e Adolescência: Pesquisa e Intervenção (pp. 147-171). São Paulo: Casa do Psicólogo.

Ellsberg, M. C., Winkvist, A., Peña, R., \& Stenlund, H. (2001). Women's strategic responses to violence in Nicaragua. Journal of Epidemiology and Community Health, 55, 547-555.

Falcke, D. \& Wagner, A. (2005). A dinâmica familiar e o fenômeno da transgeracionalidade: Definição de conceitos. Em A. Wagner (Org.), Como se perpetua a família? A transmissão dos modelos familiares (pp. 25-46). Porto Alegre: EDIPUCRS.

Folkman, S. \& Lazarus, R. (1985). If it changes it must be a process: Study of emotion and coping during three stages of a College examination. Journal of Personality and Social Psychology, 48(1), 150-170.

Folkman, S. \& Moskowitz, J. (2004). Coping: Pitfalls and promise. Annual Rewiew of Psychology, 55, 745-74.

Gadoni-Costa, L. M. \& Dell'Aglio, D. D. (2009). Mulheres em situação de violência doméstica: vitimização e coping. Gerais: Revista Interinstitucional de Psicologia, 2(2), 151-159.

Gomes, N. P., \& Diniz, N. M. F. (2008). Homens desvelando as formas da violência conjugal. Acta Paulista de Enfermagem, 21(2), 262-267. 
Goodman, L., Dutton, M., Weinfurt, K., \& Cook, S. (2005). The intimate partner violence strategies index: Development and application. Violence Against Women, 9(2), 163186.

Grossi, P. \& Aguinsky, B. (2001). Por uma nova ótica e uma nova ética na abordagem da violência contra mulheres nas relações conjugais. Em P. K. Grossi \& G. C. Verba (Orgs.), Violências e gênero: Coisas que a gente não gostaria de saber (pp.1945). Porto Alegre: EDIPUCRS.

Hart, B. (1993). Battered women and the criminal justice system. American Behavioral Scientist, 36, 624-638.

Johnson, M. \& Ferraro, K. (2000). Research on domestic violence in the 1990's: Making distinctions. Journal of Marriage and Family, 62, 948-963.

Laville, C. \& Dionne, J. (1999). A construção do saber: Manual de metodologia da pesquisa em ciências humanas. Porto Alegre: UFMG.

Lazarus, R. \& Folkman, S. (1984). Stress, appraisal, and coping. New York: Springer.

Lerner, C. \& Kennedy, L. (2000). Stayleave decision making in battered women: Trauma, coping and selfefficacy. Cognitive Therapy and Research, 24(2), 215-232.

Löbman, R., Greve, W., Wetzels, P., \& Bosold, C. (2003). Violence against women: Conditions, consequences and coping. Psychology, Crimes \& Law, 9(4), 309-331.

Matud, M. (2004). Autoestima en la mujer: Análisis de su relevancia en la salud. Avances em Psicología Latinoamericana, 22, 129-140.

Monteiro, C. (2005). Marcas no corpo e na alma de mulheres que vivenciam a violência conjugal: Uma compreensão pela Enfermagem. Tese de Doutorado, Programa de PósGraduação em Enfermagem, Universidade Federal do Rio de Janeiro (UFRJ), Rio de Janeiro.
Muszkat, M. (2002). Violência e intervenção. Em M. Corrêa (Ed.), Gênero e cidadania (pp. 47-57). Campinas: Pagu/Núcleo de Estudos de Gênero/Unicamp.

Organização das Nações Unidas, ONU (2006). Estudio a fondo sobre todas las formas de violencia contra la mujer. Retirado em 13/06/2008 de http://www.onu.org.

Pais-Ribeiro, J. \& Santos, C. (2001). Estudo conservador de adaptação do Ways of Coping Questionnaire a uma amostra e contexto portugueses. Análise Psicológica, 4(19), 491-502.

Parker, G. \& Lee, C. (2007). Relationship among abuse characteristics, coping strategies, and abused women's psychological health: A path model. Journal of Interpersonal Violence, 22(9), 1184-1198.

Rabello, P. \& Caldas-Junior, A. (2007). Violência contra a mulher, coesão familiar e drogas. Revista de Saúde Pública, 41(6), 970-978.

Ravagnani, L., Domingos, N., \& Miyazaki, M. C. (2007). Qualidade de vida e estratégias de enfrentamento em pacientes submetidos a transplante renal. Estudos de Psicologia, 12(2), 177-184.

Ribeiro, M., Ferriani, M., \& Reis, J. (2004). Violência sexual contra crianças e adolescentes: Características relativas à vitimização nas relações familiares. Cadernos de Saúde Pública, 20(2), 456-464.

Rodrigues, A. \& Chaves, E. (2008). Fatores estressantes e estratégias de coping dos enfermeiros atuantes em oncologia. Revista Latino-Americana de Enfermagem, 16(1), 24-28.

Sabina, C. \& Tindale, R. S. (2008). Abuse characteristics and coping resources as predictors of problem-focused coping strategies among battered women. Violence Against Women, 14(4), 437-456.

Schraiber, L., D'Oliveira, A., França-Junior, I., Diniz, S., Portella, A., Ludermir, A., 
Valença, O., \& Couto, M. (2007). Prevalência da violência contra a mulher por parceiro íntimo em regiões do Brasil. Revista de Saúde Pública, 41(5), 797-807.

Seidl, E., Tróccoli, B., \& Zannon, C. (2001). Análise fatorial de uma medida de estratégias de enfrentamento. Psicologia: Teoria e Pesquisa, 17(3), 225-234.

Siegel, J. \& Williams, L. (2001). Risk factors for violent victimization of women: A prospective study, Final Report. National Institute of Justice. Retirado em 20/07/2010 de http://www.ncjrs.org/pdffiles1/nij/grant s/189161.pdf

Swan, S. \& Sullivan, T. (2009). The resource utilization of women who use violence in intimate relationships. Journal of Interpersonal Violence, 24(6), 940-958.

Takano, Y. (2006). Coping with domestic violence by Japanese Canadian women. Em P. T. Wong, L. C. Wong, \& W. J. Lonner (Eds.), Handbook of multicultural perspectives on stress and coping (pp. 319-360). New York: Springer.

Waldrop, A. \& Resick, P. (2004). Coping among adult female victims of family violence. Journal of Family Violence, 19, 291-302.

Yin, R. (2005). Estudo de caso: Planejamento e métodos. Porto Alegre: Bookman. 